\title{
Equipment Layout Improvement for Large-Scale Hot Cell Facility Logistics
}

\author{
Seungnam Yu, Jaehoon Lim, Hunsuk Im, and Hyojik Lee \\ Korea Atomic Energy Research Institute, 111 Daedeok-daero, 989Beon-Gil, Yuseong-Gu, Daejeon, Republic of Korea \\ Correspondence should be addressed to Seungnam Yu; snyu@kaeri.re.kr
}

Received 12 April 2017; Accepted 31 July 2017; Published 19 October 2017

Academic Editor: Carlo Sborchia

Copyright (C) 2017 Seungnam Yu et al. This is an open access article distributed under the Creative Commons Attribution License, which permits unrestricted use, distribution, and reproduction in any medium, provided the original work is properly cited.

\begin{abstract}
This study presents approaches to equipment layout improvement for a large-scale hot cell facility. First, the original facility layout and target process are introduced, including the basic information and specifications. Second, the flow of process materials is analyzed and the relationships are evaluated in detail using a "from-to chart" and a "relationship chart" for the original layout, and the logistics are simulated using the selected discrete event simulator to calculate the traveling distances of process materials handled by teleoperated material handling systems. Third, the original layout is modified using the total closeness rating (TCR), and the efficiency and usage of the material handling system are calculated and compared with the original case to evaluate the efficiency improvement of the modified layout. This modification process, which included load reduction, enabled those aspects of the material handling system that would need to be changed to be identified; these changes were suggested by a quantitative analysis of the logistics between each pair of stations and intuitive rearrangement based on charts and figures. These approaches could be an initial step in the large-scale hot cell design process, with future work to follow.
\end{abstract}

\section{Introduction}

Generally, the design of industrial factory layouts requires the layout to be optimized in advance [1]. Various methodologies for ordinary industrial facility design have been proposed and applied in practice, and these approaches are regarded to be well proven in the analytic, virtual, and practical evaluation stages [2-5]. As an extension of existing applications of industrial areas, this study attempts to apply these approaches to the design of a specified nuclear facility. Nuclear facilities such as hot cells have many kinds of constraints because of the intrinsic hazardous nature of the work performed in confined areas, for instance, work involving materials emitting radioactive particles and corrosive chemicals and fumes. To perform safe experiments in such kind of isolated condition, teleoperation systems or well-developed tools hardened to radiation are essential [6]. Moreover, a large-scale experimental facility or production line in nuclear environments must be designed such that it is isolated from external influences; simultaneously, the layout design needs to be appropriate to support productivity and efficiency. In this regard, this study proposes a design that aims to improve the efficiency of the original hot cell layout using an industrial approach yet also takes the basic hot cell design philosophy into consideration. Although these kinds of studies are commonly reported for industrial areas [7-11], similar research in the nuclear area appears to be rare. The main topics in this study are as follows. First, the conceptually designed hot cell facility layout for large-scale pyroprocessing, including the floor plan and process logic, is introduced. Second, the flows of process materials are analyzed, and the relationships between each pair of process equipment components are evaluated using a "from-to chart" and a "relationship chart" for the original layout. The logistics are simulated using a selected discrete event simulator to calculate the traveling distances of process materials handled by teleoperated material handling systems. Third, the original layout is modified using the total closeness rating (TCR), after which the efficiency and usage of material handling systems are recalculated and compared with the results obtained for the original layout. 


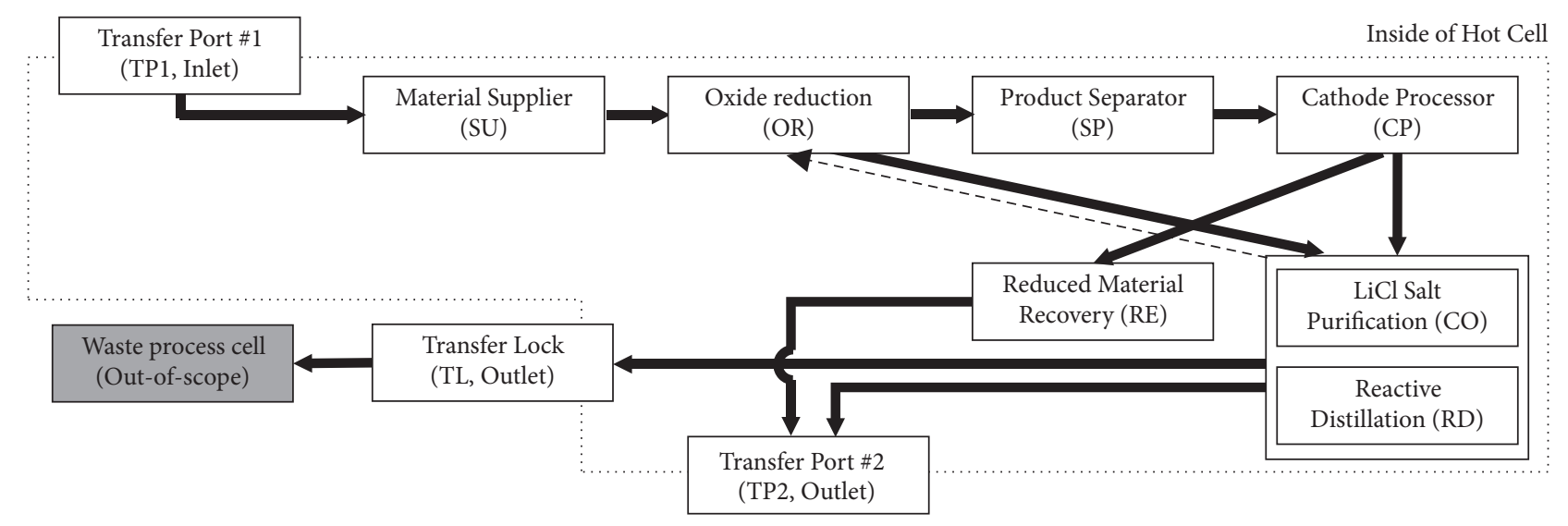

- Material transfer (feed-forward process)
_- Material transfer (feedback process)

FIGURE 1: Oxide reduction process performed in the hot cell at the target facility.

\section{Materials and Methods}

2.1. Process Considered for Layout Design. Although pyroprocessing comprises a number of unit processes [12-14], this study only considered the oxide reduction process. This process receives oxide spent fuel (SF) feed material in the form of porous pellets fabricated in the Head-End Process Cell. Then, the oxide SF is reduced to metallic form in a bath of molten lithium chloride $(\mathrm{LiCl})$ by using an oxide reduction process. The oxide pellets that are reduced to the metal contain transition elements, including actinides and a certain fraction of rare earth elements. As the next step, the reduced metal is then subjected to a cathode processing process to remove the residual salt contained in the reduced metal by way of distillation. The reduced metal is subsequently transferred to a recovery process to separate the fission products from the metal. Finally, this metal is transported to an electrolytic recovery process that forms the next step. The $\mathrm{LiCl}$ salt remaining in the oxide reduction equipment and the cathode processing equipment contains most of the fission products, including cesium, strontium, and others. The $\mathrm{LiCl}$ is extracted from the oxide reduction equipment and the products of $\mathrm{LiCl}$ from the cathode processing equipment are transferred to a $\mathrm{LiCl}$ salt purification process for recycling [15]. Figure 1 presents a flow diagram of the seven unit processors (Material Supplier, Oxide Reducer, Product Separator, Cathode Processor, LiCl Salt Purifier, Reactive Distiller, and Material Recovery Equipment) included in this study with the three gates (TP1, TP2, and TL) used for material transfer from/to the oxide reduction cell.

2.2. Previous Design of a Large-Scale Argon Cell Facility. The Korea Atomic Energy Research Institute (KAERI) recently performed conceptual design of a demonstration-scale hot cell facility for pyroprocessing. In recent years, all process equipment required for integrated processes has been examined based on experience acquired during the PyRoprocess Integrated inactive DEmonstration facility (PRIDE) project
[16]. PRIDE is a pilot facility used to simulate integrated pyroprocessing at an engineering-scale in an argon atmosphere. The dimensions of the main operation cell of PRIDE are $40.3 \mathrm{~m}$ in length, $4.8 \mathrm{~m}$ in width, and $6.4 \mathrm{~m}$ in height and the cell is located on the second floor. PRIDE utility systems are operated on the first floor to maintain an argon atmosphere and their operational requirements that determine the concentrations of oxygen and moisture be maintained below $50 \mathrm{ppm}$. In particular, all PRIDE process equipment has a capacity of $50 \mathrm{~kg}$ per batch, and depleted uranium with surrogate materials is applied to evaluate the performance of engineering-scale pyroprocessing. Major process equipment installed in PRIDE includes an electrolytic reducer, Cathode Processor, electrowinner, and waste molten salt treatment apparatus. Remote handling tasks such as process operation and maintenance in PRIDE are performed using 17 pairs of mechanical Master-Slave Manipulator (MSM) and a Bridge-transported Dual-arm Servo-Manipulator (BDSM), and material and equipment transfer are performed using crane systems [17]. The demonstration-scale hot cell facility of this study is as a new one that is to supersede PRIDE and is capable of satisfying the increased requirements of larger scale facilities. Essentially, this facility is required to process hazardous materials such as spent nuclear fuel, which must be processed in a highly shielded area, namely, in a hot cell isolated from the operator's working area. Moreover, a dry inert atmosphere required by the electrometallurgical process takes place in the cells. The considered facility must also achieve the goal of significantly increased annual production beyond that of the previous facility; therefore, several parts of the production line need to be automated.

2.3. New Design Concept of a Large-Scale Hot Cell Facility. This new facility is spread across several floors, including the main processing area and utilities areas. This facility is considered as a nuclear-chemical processing plant based on largescale electrochemical reactions. In particular, chloride and 


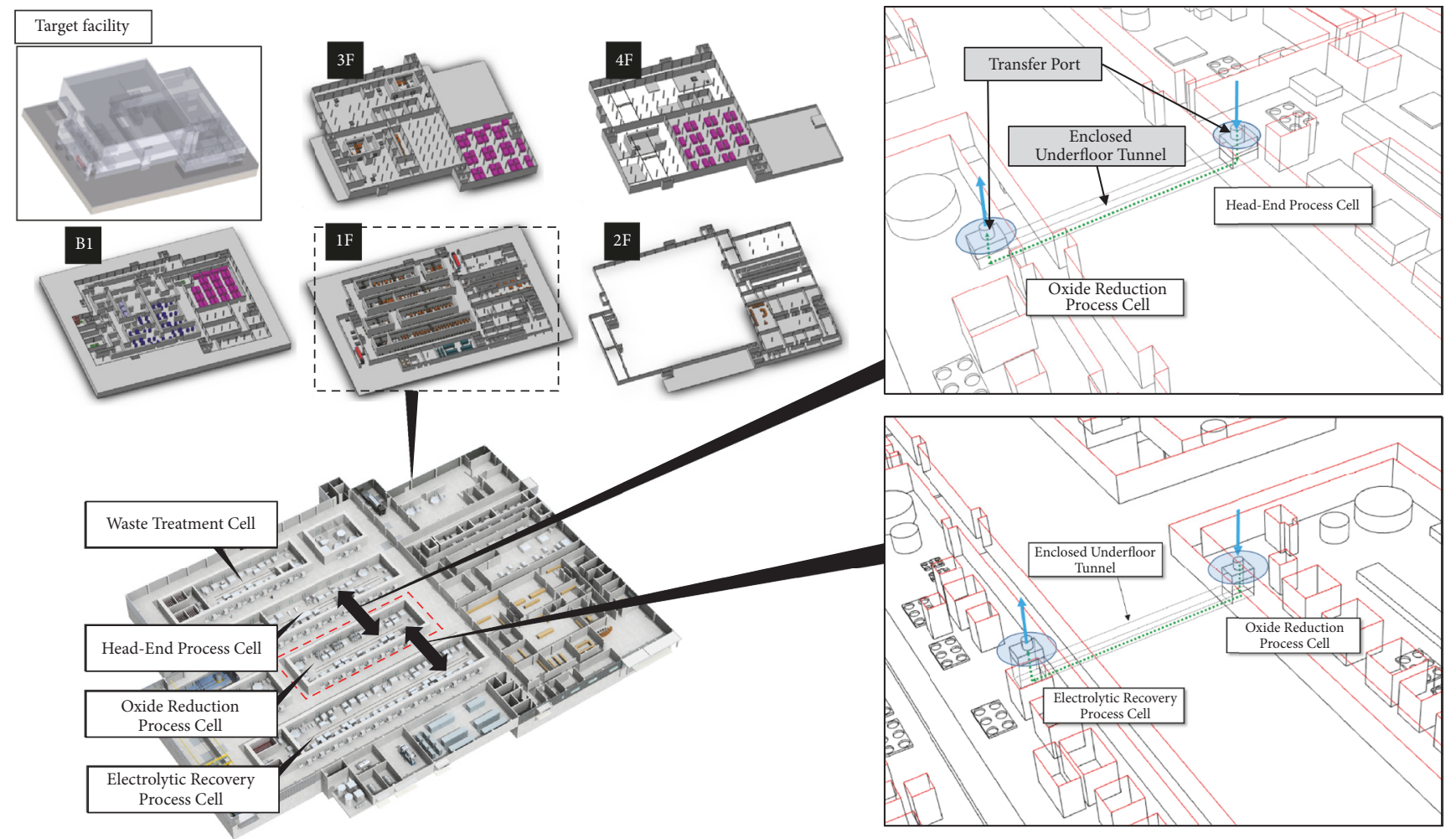

FIGURE 2: Floor plans and concept of the transportation tunnel between hot cells of the considered facility.

salt are applied to perform the electrochemical reaction of the target materials in a high-temperature furnace. Moreover, to meet the required annual production rate, the scale of this plant is larger and it uses more auxiliary equipment than the lab- or engineering-scale equipment proposed earlier.

The conceptually designed facility layouts shown in Figures 2 and 3 mostly included the existing process equipment that was used in PRIDE and several kinds of newly designed equipment that were added to meet the larger scale of the process. Therefore, this kind of initially designed layout has relatively low relevance to the updated design proposed in this study because the relationships between existing main processors and newly added auxiliary equipment are not considered in detail. The goal of this study is to rationalize equipment connections and reduce the burden of remote handling systems by, for example, minimizing the total traveling distance.

2.4. Layout Improvement Strategy. Basically, pyroprocessing includes many processes for fuel conditioning and complex material flows. Since it consists almost entirely of batch-type processes, even though some kinds of unit processes are similar to continuous processes, the use of a discrete event system for modeling is preferred if the main concerns are not the electrochemical reactions within a single batch operation [15]. Additionally, every step at each component of the process equipment, including the mass transfer and material handling system operations, can be traced through discrete event simulation. In this regard, to improve the preliminary process layout, this study proposes the following approaches. First, the material flow and the usage of material handling systems for the preliminary designed layout are simulated using a discrete event simulator during the specified period. Then, the relationship between the equipment is analyzed in terms of the load transfer and the number of operations. Additionally, the preliminary designed layout is evaluated using conventional layout analysis methods such as activity relationship charts to derive the TCR value, and this one is used to rearrange the layout of the process equipment. Finally, the modified layout is again simulated to compare the load of the teleoperation system to that in the considered facility design. In addition, the efficiencies of each component of the process equipment are compared using a parametric anaysis. To simulate the discrete events of the considered process in the designed layout, this study applied WITNESS ${ }^{\circledR}$ as shown in Figure 4. WITNESS is the Lanner Group's simulation software package. It is suited to a variety of production and storage layout and logistical modeling scenarios [18].

\section{Results and Discussion}

3.1. Basic Approach for the Evaluation of a Layout Efficiency. The flow of large-volume materials was measured and the relationship of process equipment was quantitatively evaluated by using a "from-to chart" and a "relationship chart" simultaneously. In particular, an existing quantitative technique [19-22] was used to analyze the considered layout to assign appropriate equipment positions. In this 


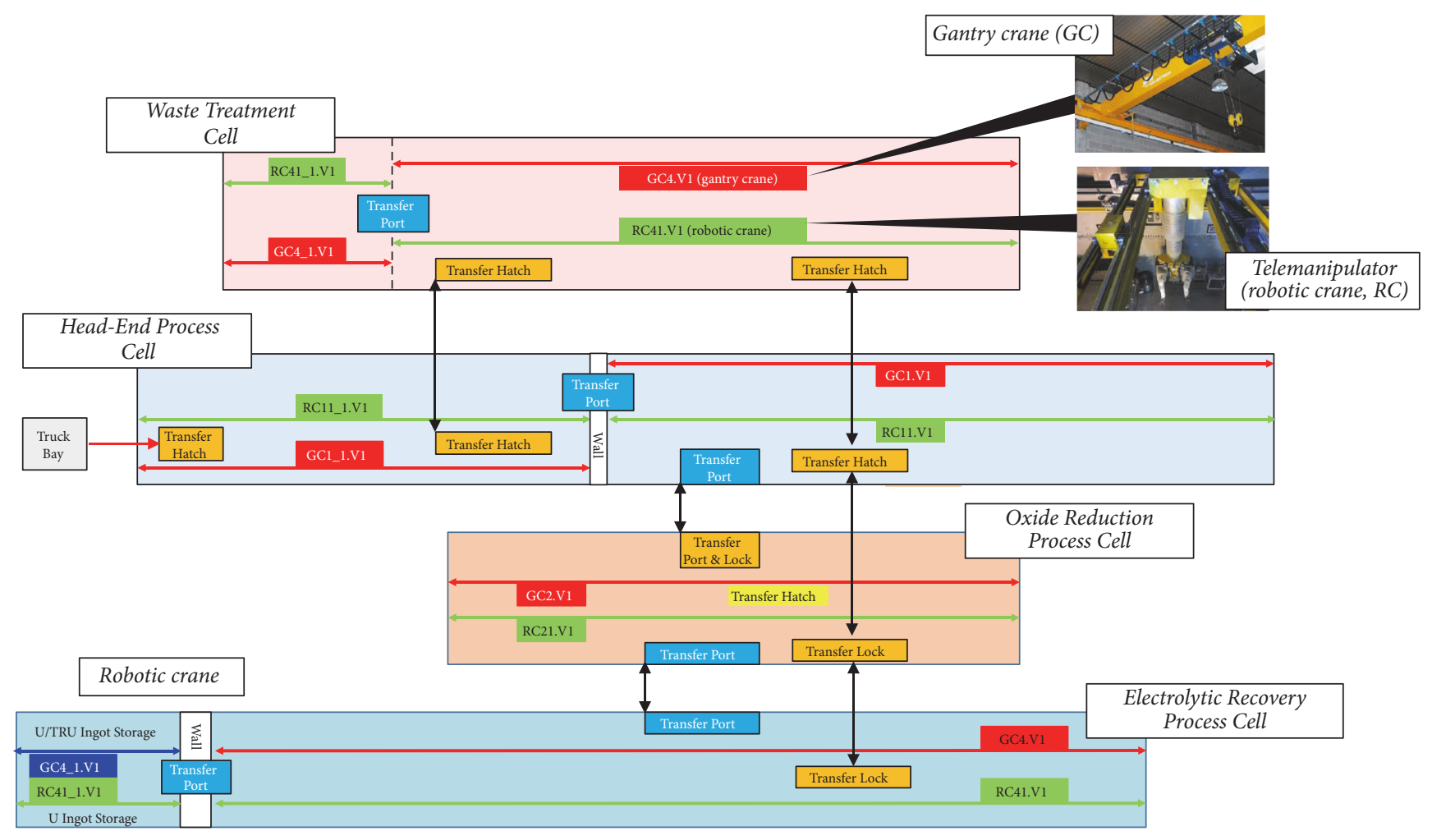

FIGURE 3: Transportation system of the entire facility. The transportation systems covered by this study are the gantry crane GC2.V1 and the robotic crane RC21.V1 in the oxide reduction process cell.

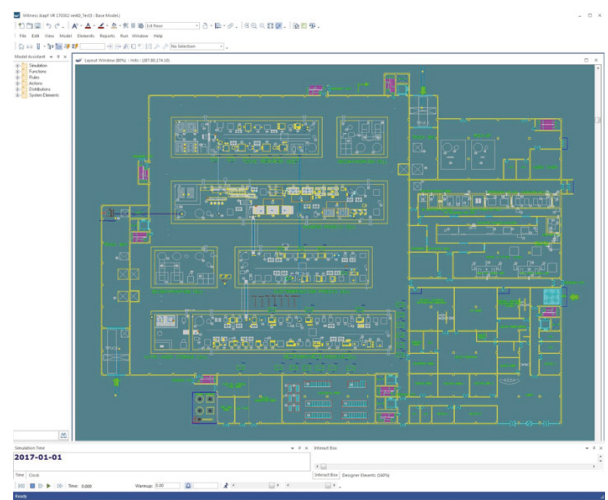

FIGURE 4: Layout modeling of the target facility using WITNESS.

study, the equipment component relating to an individual process is referred to as a station. Several alternatives were generated by scoring the relationships among the stations and rearranging them using the prescribed approach. The alternatives were evaluated by calculating the cost function, which was formulated using the properties of the travel distance for each combination of components, that is, the cost of traveling and the load per movement. This method requires the initial values of the original layout as its input and proceeds according to the following steps:

(1) Build a traveling distance matrix $\left[D_{1}\right]$ using the original layout.
(2) Build a "number of movements" matrix $[M]$ and calculate the total moving weight between stations.

(3) Calculate a "load per movement" matrix $[L]$ using the information in step (2).

(4) Calculate the efficiency of the original layout as eff ${ }_{1}=$ $1-\left([L] /\left[D_{1}\right][L]\right)$.

(5) To modify the layout, build the activity relationship chart using the information in step (3) and score the total closeness rating (TCR).

(6) The first station placed in the modified layout is the one with the greatest TCR value. If a tie exists, choose the station with more $A$ relationships.

(7) The second station must have an $A$ relationship with the first one. If a tie exists, choose the station with the greatest TCR value. If a station has an $X$ relationship with the second station, it is placed next-to-last or last in the layout. If a tie exists, choose the station with the smallest TCR value.

(8) The third station must have an $A$ relationship with one of the placed stations. If a tie exists, choose the station with the greatest TCR value.

(9) The procedure continues until all stations have been placed, and this completes the layout modification.

(10) Calculate the efficiency eff ${ }_{2}$ using the modified distance matrix $\left[D_{2}\right]$ and matrix $[L]$, and compare the results with those of step (4). 


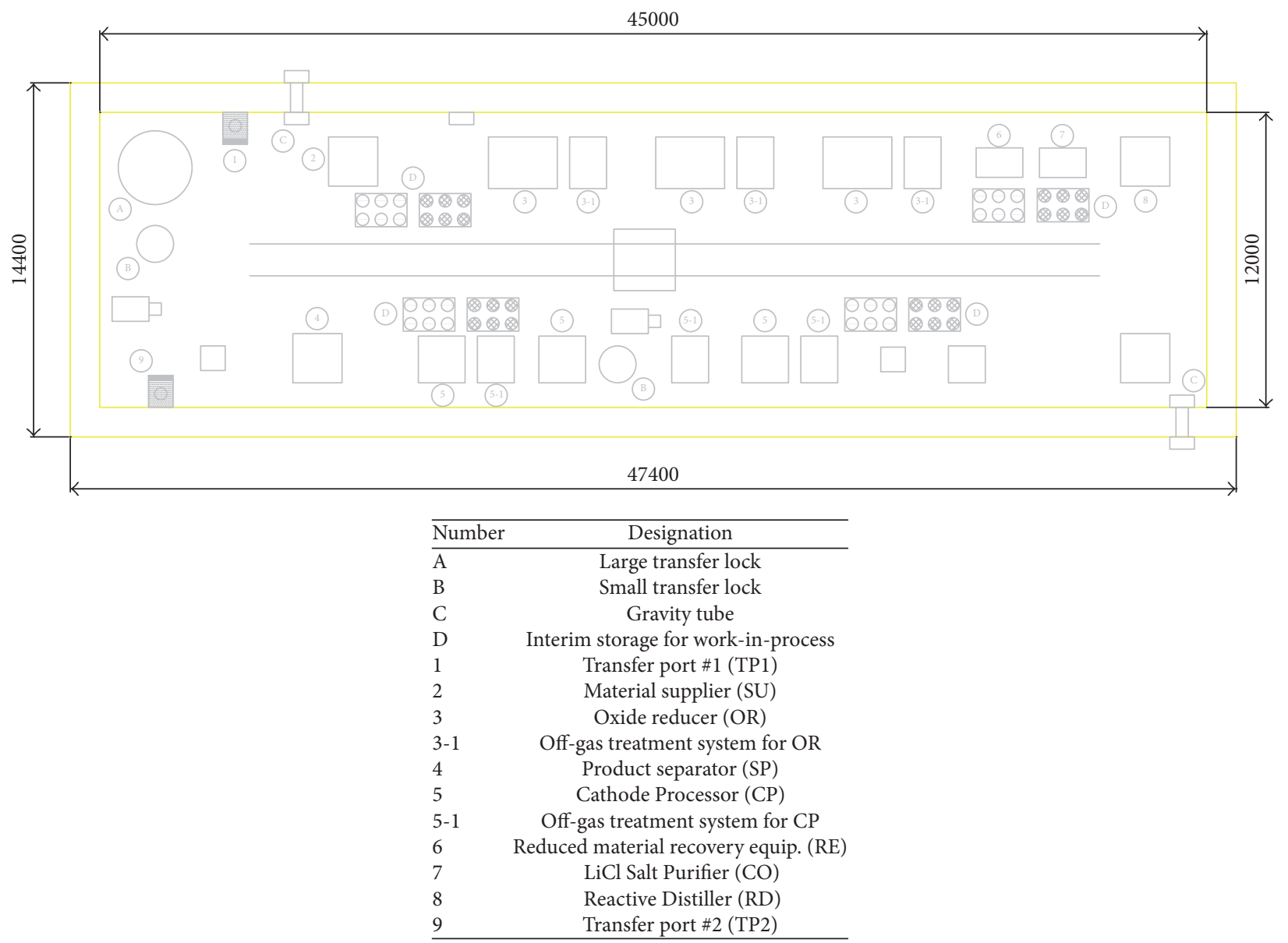

FIGURE 5: Drawing of the original layout design.

TABLE 1: Equipment list for the oxide reduction cell.

\begin{tabular}{lcc}
\hline Number & Symbol & Name of station (refer to Figure 1) \\
\hline 1 & TP1 & Transfer Port (connected with Head-End Cell) \\
3 & SU & Material Supplier \\
4 & OR & Oxide Reducer \\
5 & SP & Product Separator \\
6 & CP & Cathode Processor \\
7 & RE & Reduced Material Recovery Equip. \\
8 & CO & LiCl Salt Purification \\
9 & RD & Reactive Distiller \\
\hline
\end{tabular}

3.2. Efficiency Analysis of the Original Layout. The oxide reduction cell was originally designed as shown in Figure 5 based on the annual production goal. Even though the layout was designed in consideration of the area necessary to install the equipment required for the entire process, this area contained excessive marginal space. The present layout improvement process is expected to not only support effective operation of the remote handling system but also reduction of the required hot cell area. Table 1 contains the list of equipment installed in the oxide reduction cell shown in Figure 5.
Figure 6(a) shows a simplified layout of the drawing in Figure 5. The numbers in Figure 6(a) are identical to those in Table 1. Additionally, " $X-1$ " labels such as " $3-1$ " indicate accessories of equipment " $X$," and it is assumed that these belong to " $X$ " as part of the same unit. This process enables many kinds of units in Figure 5 to be either omitted or simplified. Figure 6 depicts the entire process whereby simplification of the equipment layout is achieved in order to derive the geometric relationships among the equipment.

The efficiency of the considered layout is calculated by generating the distance matrix $\left[D_{1}\right]$ as in Table 2 using 


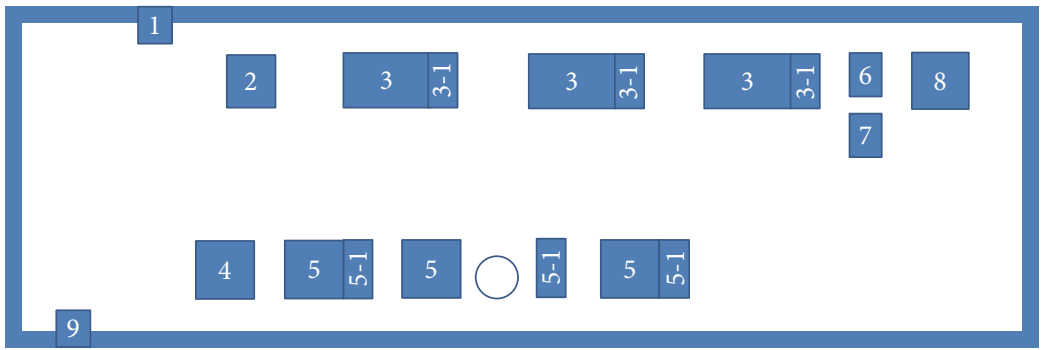

(a) Simplification of the layout drawing

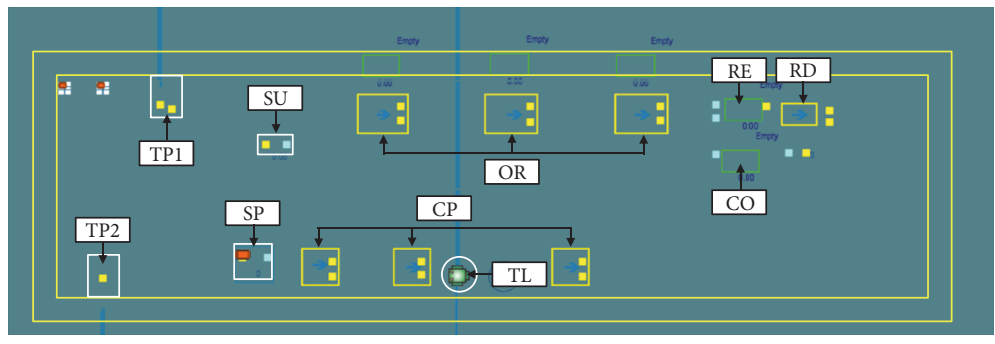

(b) Modeling of the layout on the WITNESS

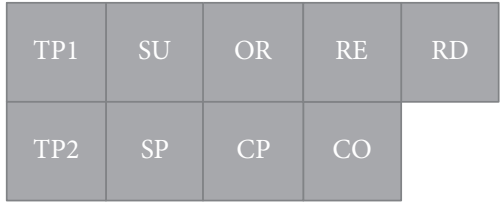

(c) Geometric relationship between process equipment derived from the simplified layout

FIGURE 6: Analysis of the original layout of the considered oxide reduction process cell.

TABLE 2: Distance matrix of the original layout $\left[D_{1}\right]$.

\begin{tabular}{lccccccccc}
\hline & TP1 & SU & OR & SP & CP & RE & CO & RD & TP2 \\
\hline TP1 & - & 1 & 2 & 2 & 3 & 3 & 4 & 4 & 1 \\
SU & 1 & - & 2 & 1 & 2 & 2 & 3 & 3 & 2 \\
OR & 2 & 1 & - & 2 & 1 & 1 & 2 & 2 & 3 \\
SP & 2 & 1 & 2 & - & 1 & 3 & 2 & 4 & 1 \\
CP & 3 & 2 & 1 & 1 & - & 2 & 1 & 3 & 2 \\
RE & 4 & 2 & 1 & 3 & 2 & - & 1 & 1 & 4 \\
CO & 4 & 3 & 2 & 2 & 1 & 1 & - & 2 & 3 \\
RD & 4 & 3 & 2 & 4 & 3 & 1 & 1 & - & 5 \\
TP2 & 1 & 2 & 3 & 1 & 2 & 4 & 3 & 5 & - \\
\hline
\end{tabular}

TABLE 3: "Number of movements" matrix $[M]$.

\begin{tabular}{lccccccccc}
\hline & TP1 & SU & OR & SP & CP & RE & CO & RD & TP2 \\
\hline TP1 & - & 68 & 0 & 0 & 0 & 0 & 0 & 0 & 0 \\
SU & 0 & - & 900 & 0 & 0 & 0 & 0 & 0 & 0 \\
OR & 0 & 0 & - & 450 & 0 & 0 & 45 & & 0 \\
SP & 0 & 0 & 0 & - & 450 & 0 & 0 & 0 & 0 \\
$\mathrm{CP}$ & 0 & 0 & 0 & 0 & - & 388 & 388 & & 0 \\
$\mathrm{RE}$ & 0 & 0 & 0 & 0 & 0 & - & 0 & 388 & 0 \\
$\mathrm{CO}$ & 0 & 0 & 40 & 0 & 0 & 0 & - & 0 & 0 \\
$\mathrm{RD}$ & 0 & 0 & 40 & 0 & 0 & 0 & 0 & - & 300 \\
$\mathrm{TP} 2$ & 0 & 0 & 0 & 0 & 0 & 0 & 300 & 0 & - \\
\hline
\end{tabular}

the information shown in Figure 6(c). Additionally, other matrices such as the "number of movements" and "load per movement" matrices, presented in Tables 3 and 4, are generated for every pair of equipment based on the practical balance of the calculated mass flow of the target facility. This
TABLE 4: "Load per movement" matrix $[L]$ (units: $\mathrm{kg}$ ).

\begin{tabular}{lccccccccc}
\hline & TP1 & SU & OR & SP & CP & RE & CO & RD & TP2 \\
\hline TP1 & - & 450 & 0 & 0 & 0 & 0 & 0 & 0 & 0 \\
SU & 0 & - & 30 & 0 & 0 & 0 & 0 & 0 & 0 \\
OR & 0 & 0 & - & 100 & 0 & 0 & 3 & 0 & 0 \\
SP & 0 & 0 & 0 & - & 200 & 0 & 0 & 0 & 0 \\
CP & 0 & 0 & 0 & 0 & - & 199.5 & 0.5 & 0 & 0 \\
RE & 0 & 0 & 0 & 0 & 0 & - & 0 & 199.5 & 0 \\
CO & 0 & 0 & 0.5 & 0 & 0 & 0 & - & 0 & 0 \\
RD & 0 & 0 & 0.5 & 0 & 0 & 0 & 0 & - & 199 \\
TP2 & 0 & 0 & 0 & 0 & 0 & 0 & 3 & 0 & - \\
\hline
\end{tabular}

process makes the following assumptions for each of the processes under consideration.

(1) The amounts of materials supplied to the equipment apart from main process are not considered in this flow.

(2) Materials distributed from the "CP" are separated and supplied to the next equipment component simultaneously.

Using these matrices, the efficiency of the original facility can be calculated as follows:

$$
\operatorname{eff}_{1}(\%)=\frac{\sum_{i=1}^{\mathrm{rw}} \sum_{j=1}^{\mathrm{cl}} L(i, j)}{\sum_{i=1}^{\mathrm{rw}} \sum_{j=1}^{\mathrm{cl}} L(i, j) D_{1}(i, j)} \times 100=54.96 \% \text {, }
$$

where $i$ is $i$ th row; $j$ is $j$ th column; rw is number of rows; $\mathrm{cl}$ is number of columns. 


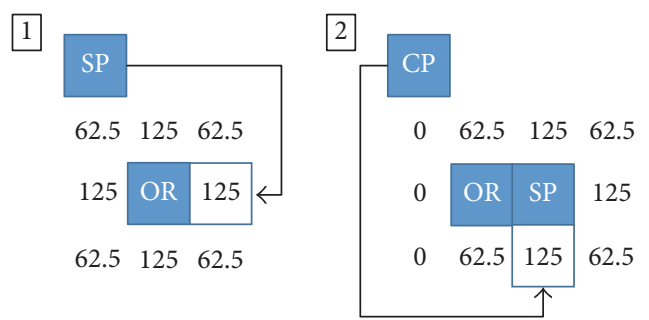

(a) Arrangement of OR, SP, and $\mathrm{CP}$
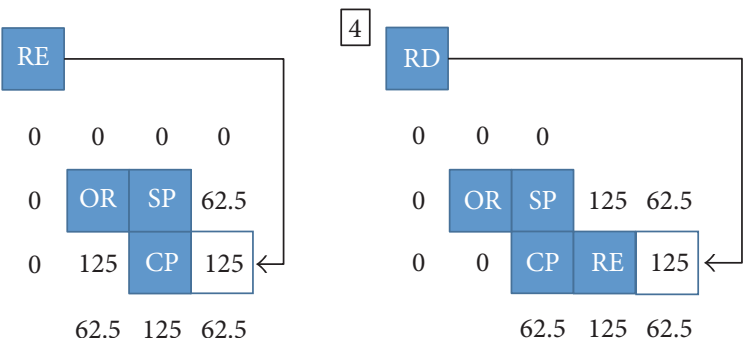

(b) Arrangement of RE and RD

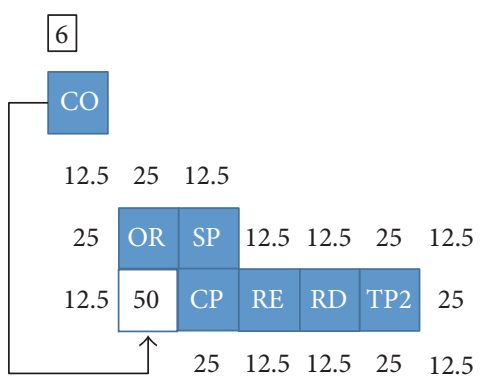

(c) Arrangement of TP2 and CO

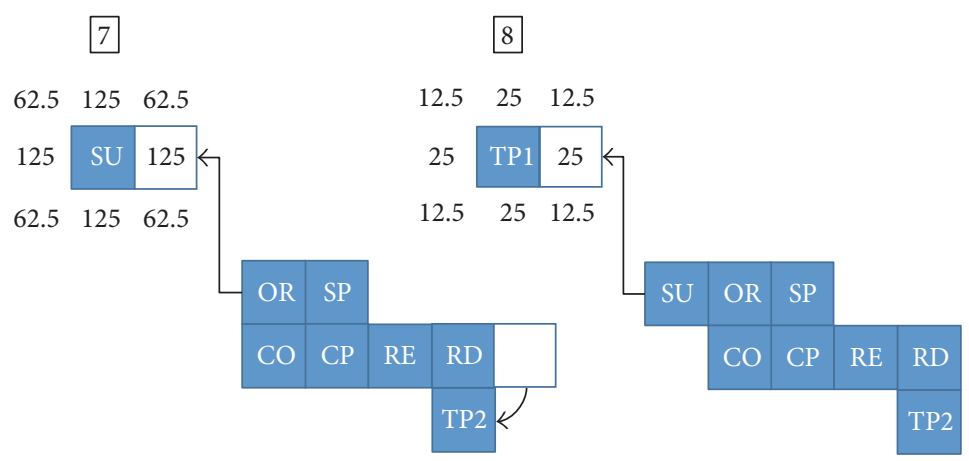

(d) Arrangement of SU and TP1

FIGURE 7: Layout modification process.

TABLE 5: Activity relationship chart.

\begin{tabular}{lcccccccccc}
\hline & TP1 & SU & OR & SP & CP & RE & CO & RD & TP2 & TCR \\
\hline TP1 & - & $E$ & $U$ & $U$ & $U$ & $U$ & $U$ & $U$ & $U$ & 25 \\
SU & $O$ & - & $A$ & $U$ & $U$ & $U$ & $U$ & $U$ & $U$ & 126 \\
OR & $U$ & $O$ & - & $A$ & $U$ & $U$ & $E$ & $U$ & $U$ & 151 \\
SP & $U$ & $U$ & $U$ & - & $A$ & $U$ & $U$ & $U$ & $U$ & 125 \\
CP & $U$ & $U$ & $U$ & $U$ & - & $A$ & $E$ & $U$ & $U$ & 150 \\
RE & $U$ & $U$ & $U$ & $U$ & $U$ & - & $U$ & $A$ & $U$ & 125 \\
CO & $U$ & $U$ & $I$ & $U$ & $U$ & $U$ & - & $U$ & $U$ & 5 \\
$\mathrm{RD}$ & $U$ & $U$ & $I$ & $U$ & $U$ & $U$ & $U$ & - & $A$ & 130 \\
$\mathrm{TP} 2$ & $U$ & $U$ & $U$ & $U$ & $U$ & $U$ & $E$ & $U$ & - & 25 \\
\hline
\end{tabular}

3.3. Layout Improvement of the Original Layout. This section describes the layout modification of the considered stations. This modification requires the levels of the relationships between the stations to be defined. Equation (2) shows the rules applied in this paper to assign the value of the relationship. Table 5 can be generated from the information in Tables 2-4. Based on Table 5 and the rules of (2), a modified layout can be constructed as in Figure 7. As shown this figure, the first station placed in the new layout is the one with the greatest TCR value. If there is a tie value, then the station with a larger number of $A$ or $E$ relationships is chosen. The second station is the station with a relationship with the first station. If a tie exists, the station with the greatest TCR value is chosen; this process is repeated until the smallest TCR value is reached. Two activities are (fully) adjacent in a layout if they share a common border of positive length, that is, not only a point. Two activities are partially adjacent in a layout if they only share one or a finite number of points, that is, zero length and these kinds of cases have half value of TCR of the positive length case. The build-up process of the modified layout is as follows. First, it is assumed that a station is placed in the middle (position 0 ). Then, the placement of the next station is determined by evaluating all possible locations around the current layout in clockwise order beginning at the "eastern edge." The new station is located based on the greatest weighted placement (WP) value. For each position, WP is the sum of the TCR values for all pairs of adjacent 


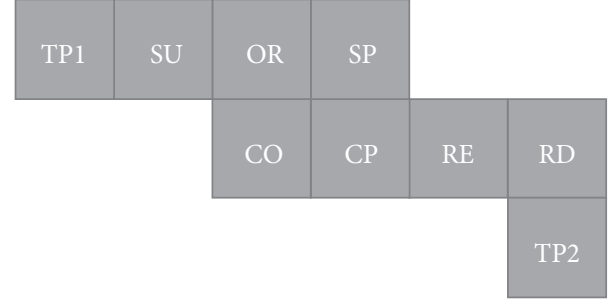

FIGURE 8: Modified layout.

stations. Based on this method, the first station "OR," which has the largest TCR value, is placed in the layout. If there is a tie, then the station with the most $A$ values is chosen. The second station is the one with a relationship with the first station (or $E$, $I$, etc.); this process is repeated to the final station. Figure 8 shows the final layout modified through the process depicted in Figure 7, and Table 6 lists the changes in the distances among the process equipment.

$$
\operatorname{TCR}(i)=\sum_{j=1}^{\mathrm{cl}} V(C(i, j))
$$

$$
\begin{aligned}
& \text { If } i=j \\
& \qquad(C(i, j))=0 . \\
& \text { Else if } C(i, j) \in\{A, E, I, O\} \\
& \qquad(C(i, j))=5^{m}, \\
& m=3 \text { if } C(i, j)=A, \\
& m=2 \text { if } C(i, j)=E, \\
& m=1 \text { if } C(i, j)=I, \\
& m=0 \text { if } C(i, j)=O .
\end{aligned}
$$

Else $C(i, j) \in\{U, X\}$

$$
\begin{aligned}
& V(C(i, j))=-n\left(5^{n+2}\right), \\
& n=0 \text { if } C(i, j)=U, \\
& n=1 \text { if } C(i, j)=X,
\end{aligned}
$$

where $V$ is closeness value; $C$ is closeness rating; $A$ is large amount and frequent moving; $E$ is large amount or frequent moving; $I$ is small amount and intermittent moving; $O$ is weak correlation; $U$ is unimportant; $X$ is undesirable

$$
\operatorname{eff}_{2}(\%)=\frac{\sum_{i=1}^{\mathrm{rw}} \sum_{j=1}^{\mathrm{cl}} L(i, j)}{\sum_{i=1}^{\mathrm{rw}} \sum_{j=1}^{\mathrm{cl}} L(i, j) D_{2}(i, j)} \times 100=99.25 \%
$$

The modified layout is applied to the WITNESS SW and the total traveling distance of the material handling system is simulated.

As mentioned above, the material handling systems for teleoperation at the considered facility are composed of a gantry crane and a robotic crane. The considered operations are performed using these systems. Every transfer between
TABLE 6: Distance matrix for the modified layout $\left[D_{2}\right]$.

\begin{tabular}{lccccccccc}
\hline & TP1 & SU & OR & SP & CP & RE & CO & RD & TP2 \\
\hline TP1 & - & 1 & 2 & 3 & 4 & 5 & 3 & 6 & 7 \\
SU & 1 & - & 1 & 2 & 3 & 4 & 2 & 5 & 6 \\
OR & 2 & 1 & - & 1 & 2 & 3 & 1 & 4 & 5 \\
SP & 3 & 2 & 1 & - & 1 & 2 & 2 & 3 & 4 \\
CP & 4 & 3 & 2 & 1 & - & 1 & 1 & 2 & 3 \\
RE & 5 & 4 & 3 & 2 & 1 & - & 2 & 1 & 2 \\
CO & 3 & 2 & 1 & 2 & 1 & 2 & - & 3 & 4 \\
RD & 6 & 5 & 4 & 3 & 2 & 1 & 3 & - & 1 \\
TP2 & 7 & 6 & 5 & 4 & 3 & 2 & 4 & 1 & - \\
\hline
\end{tabular}

individual stations is performed using a robotic crane and only the shipping operations between the inlet gate and first station and final station and the outlet gate are performed by the gantry crane in the normal operation. Table 7 contains the results of the layout modification approach proposed in this study.

The effect of travel distance reduction for the gantry crane is derived from only the distance reduction between the final station "RD" and the transfer lock "TL" in Figure 9. On the other hand, the extent to which the reduction in the distance the robotic crane needs to travel is achieved is derived from the approach considered in this study.

Moreover, the role of the robotic crane in this operation is much more important than that of the gantry crane. The reduction rate of $20 \%$ for the robotic crane achieved by this simple approach is meaningful because this result is accomplished by implementing only simple layout changes. Therefore, based upon this result, other possible adjustments could be added, such as a reduction of the distances between stations to further improve the logistical efficiency. Evidently, changing the layout of the stations could be the first step toward facility layout optimization.

3.4. Further Study for Logistics. The use of discrete event simulation allows various kinds of experiments to be performed. Another approach to evaluate the efficiency of each process would be to identify meaningful changes in the entire process based on the variable performance of the considered material handling systems. This section presents a case study of this issue. Apart from layout optimization, the discrete event simulator can be used to improve the productivity of an entire process. As shown in Figure 10, experiments could be performed by tuning the cycle time ratio of each station and speed of material handling systems. In Figure 10, case 1 shows the original rate of the OR station (Group A) and that of the group consisting of $\mathrm{CO}, \mathrm{RE}$, and $\mathrm{RD}$ (Group B). Each of cases 2 to 9 is a combination of the changed cycle times for Groups A and B (bar-type graph), and the change in productivity (completion time) is plotted for each case (line-type graph). As shown in Figures 9 and 10, possible changes to the entire process could be tested instantly in the simulator to determine the modified cycle time of each group by using several different settings for the operation speed of the crane systems. In Figure 10, the reduction ratio of the 
TABLE 7: Effect of layout modification for the operation of crane systems at the target facility.

\begin{tabular}{lcc}
\hline Content & Gantry crane & Robotic crane \\
\hline Number of operations & 193 & 1,860 \\
\hline Total travel distance per year & & $42,799.4 \mathrm{~m}$ \\
$\quad$ Before modification & $7,122.9 \mathrm{~m}$ & $33,234.0 \mathrm{~m}$ \\
After modification & $964.7 \mathrm{~m}$ & $\mathbf{2 2 . 3 \%}$ \\
\hline Reduction ratio & $\mathbf{8 6 . 4 \%}$ & \\
\hline
\end{tabular}

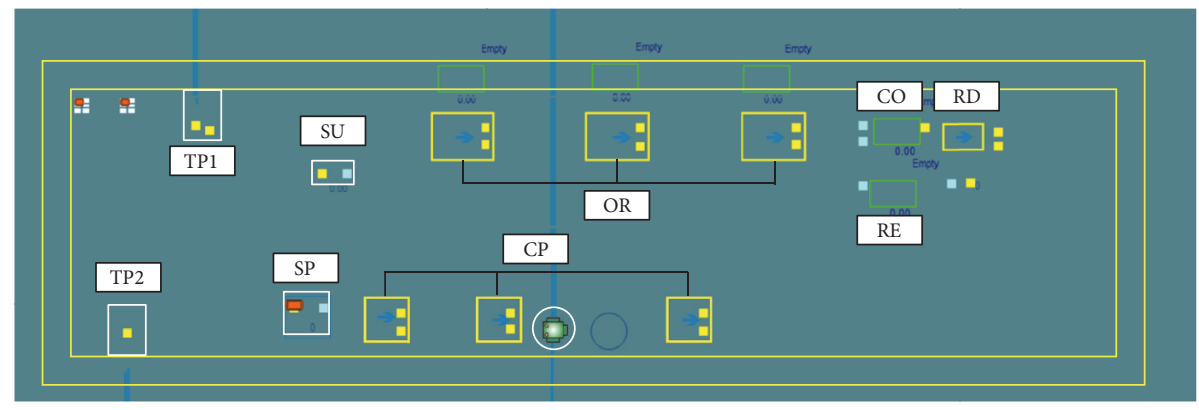

(a)

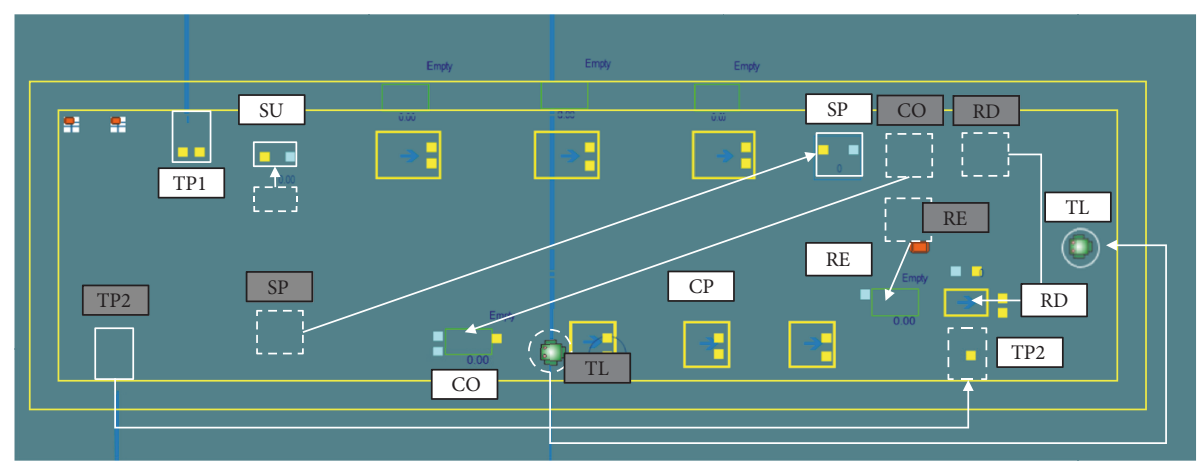

(b)

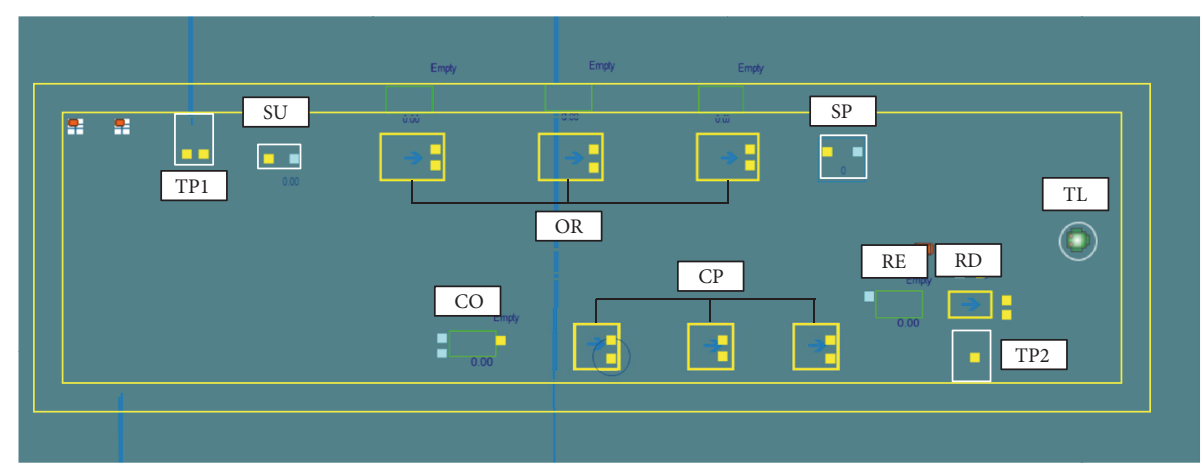

(c)

FIGURE 9: Layout modification in WITNESS ((a) initial layout; (b) layout modification; (c) after modification).

cycle time for the group comprising $\mathrm{CO}, \mathrm{RE}$, and $\mathrm{RD}$ remains small even though the cycle time scale of OR changed to 0.75 times the original value. However, if the reduction ratio of $O R$ becomes 0.5 , then the reduction ratio of group $\mathrm{B}$ falls below the original value. If the value of the cycle time becomes less than 1 , then the performance is improved above that of the original from the point of view of the cycle time. Moreover, this tendency does not change remarkably, even when the speed of the crane systems is increased twofold (cases 6 to 7). These results indicate that lowering the cycle time of the OR 


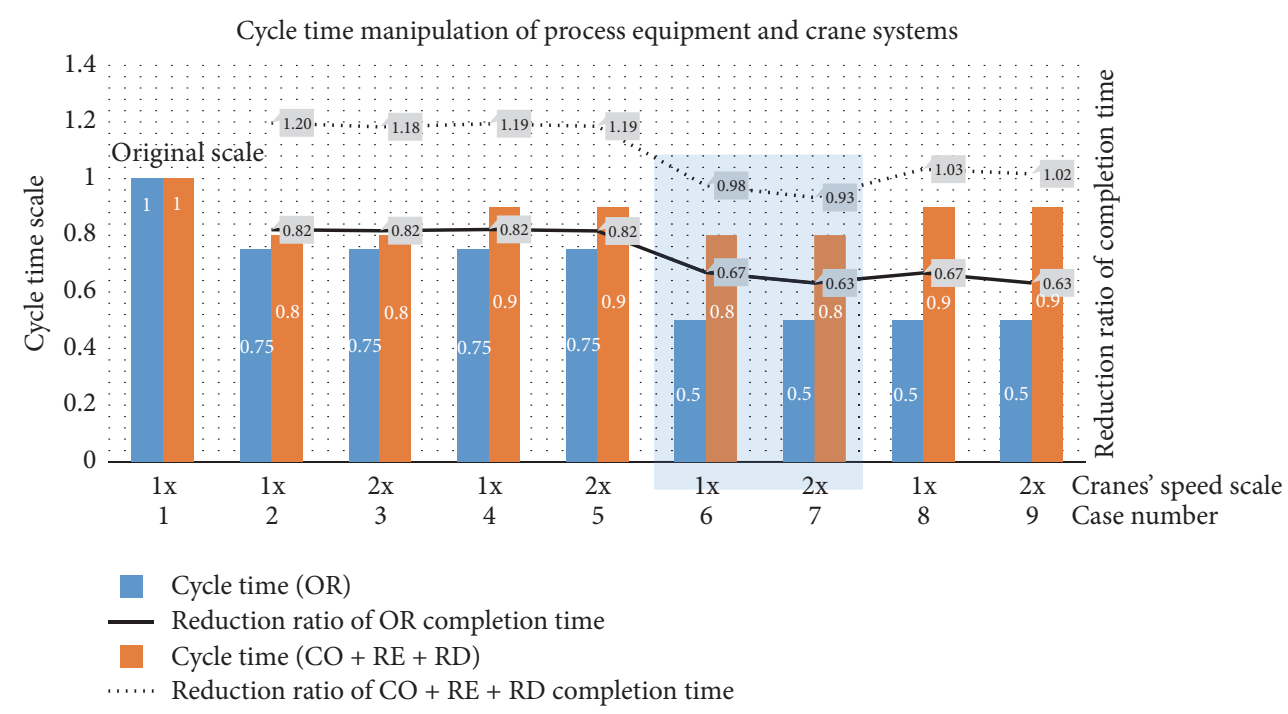

FIGURE 10: Simulation results for cycle time changes of the OR station and the CO, RE, and RD stations in the original layout using WITNESS.

station is important for improving the entire process of oxide reduction. Thus, improving the performance of OR could be considered an important design goal for this process.

\section{Conclusions}

This study proposed and verified approaches to improve the process layout of a hot cell facility using several kinds of existing layout analysis methods and a discrete event simulator. The presented simulations and experiments were based on the practical requirements indicated by the conceptual design of a demonstration-scale hot cell facility and its teleoperated crane systems for pyroprocessing. Therefore, the proposed approach was specifically tailored to applications in the nuclear field; each station and its logistical properties presented in this study were based on practically designed mass flow data of oxide reduction process expected from operations in the conceptually designed facility. The results of this study could easily be extended to other connected processes and could contribute effectively to the optimization of the design of the entire facility. The process considered in this study is part of the entire pyroprocess and each of its constituent processes is operated in an individual hot cell. Therefore, as with the presented oxide reduction process, the layout of each of the connected processes, such as the head-end process, electrolytic recovery process, and waste treatment process could be improved using this same methodology, after which they could finally be connected to each other using the exclusive gateway. Further studies regarding material handling systems for teleoperation and batch process automation applicable to hot cell facilities are anticipated as future work. In particular, more detailed requirements for hot cell design such as the basic constraints of a hot cell facility could be integrated with the proposed approach to optimize the layout design, including wall thickness, number of transfer lock systems, the thickness of lead glass considering the viewing range, and safeguard issues.

\section{Conflicts of Interest}

The authors declare that they have no conflicts of interest.

\section{Acknowledgments}

This work was supported by the Nuclear Research \& Development Program of National Research Foundation of Korea (NRF) funded by the Ministry of Science, ICT and Future Planning (MSIP).

\section{References}

[1] W. J. Hopp and M. L. Spearman, Factory Physics, Waveland Press, 2011.

[2] M. Schenk, S. Wirth, and E. Müller, Factory Planning Manual: Situation-Driven Production Facility Planning, Springer Science \& Business Media, 2009.

[3] M. A. Cohen and H. L. Lee, "Strategic analysis of integrated production-distribution systems: models and methods," Operations Research, vol. 36, no. 2, pp. 216-228, 1988.

[4] M. Iqbal and M. S. J. Hashmi, "Design and analysis of a virtual factory layout," Journal of Materials Processing Technology, vol. 118, no. 1, pp. 403-410, 2001.

[5] W. Kühn, "Digital factory - Simulation enhancing the product and production engineering process," in Proceedings of the 2006 Winter Simulation Conference, WSC, pp. 1899-1906, Monterey, CA, USA, December 2006.

[6] J. R. White, T. Sunagawa, and T. Nakajima, "Hazardous-duty robots-experiences and needs," in Proceedings of the IEEE/RSJ International Workshop, pp. 262-267, Intelligent Robots and Systems' 89. The Autonomous Mobile Robots and Its Applications, 1989.

[7] F. Longo, G. Mirabelli, and E. Papoff, "Material flow analysis and plant lay-out optimization of a manufacturing system," in Proceedings of the DAACS, IEEE, pp. 727-731, Intelligent Data Acquisition and Advanced Computing Systems: Technology and Applications, September 2005. 
[8] F. De Carlo, M. A. Arleo, O. Borgia, and M. Tucci, "Layout design for a low capacity manufacturing line: a case study," International Journal of Engineering Business Management, vol. 5, article 35, 2013.

[9] S. Benjaafar and M. Sheikhzadeh, "Design of flexible plant layouts," IIE Transactions, vol. 32, no. 4, pp. 309-322, 2000.

[10] D. Bäck and P. Johansson, "A model for effective development of plant layouts and material handling systems," Modell för effektiv utformning av fabrikslayouter och materialhanteringssystem, 2006.

[11] A. Schiffauerova, Facilities Design and Material Handling Systems, Course Notes for INDU 421, Dept. of Engineering Computer Science, Concordia University.

[12] R. W. Benedict, C. Solbrig, B. Westphal et al., "Pyroprocessing progress at Idaho national Laboratory," Advanced Nuclear Fuel Cycles and Systems (GLOBAL 2007), 2007.

[13] H. S. Lee, G. I. Park, K. H. Kang et al., "Pyroprocessing technology development at KAERI," Nuclear Engineering and Technology, vol. 43, no. 4, pp. 317-328, 2011.

[14] K. C. Song, H. S. Lee, J. M. Hur, J. G. Kim, D. H. Ahn, and Y. Z. Cho, "Status of pyroprocessing technology development in Korea," Nuclear Engineering and Technology, vol. 42, no. 2, pp. 131-144, 2010.

[15] H. J. Lee, H. S. Im, and G. I. Park, "Modeling of oxide reduction in repeated-batch pyroprocessing," Annals of Nuclear Energy, vol. 88, pp. 1-11, 2016.

[16] J. H. Ku, S. I. Moon, I. J. Cho, W. M. Choung, G. S. You, and H. D. Kim, "Development of pyroprocess integrated inactive demonstration facility," Procedia Chemistry, vol. 7, pp. 779-784, 2012.

[17] H.-S. Lee, G.-I. Park, J.-W. Lee et al., "Current status of pyroprocessing development at KAERI," Science and Technology of Nuclear Installations, vol. 2013, Article ID 343492, 11 pages, 2013.

[18] A. Waller, "WITNESS simulation software," in Proceedings of the Winter Simulation Conference, p. 436, Winter Simulation Conference, 2012.

[19] L. R. Foulds, "Techniques for facilities layout: deciding which pairs of activities should be adjacent," Management Science, vol. 29, no. 12, pp. 1414-1426, 1983.

[20] A. Kusiak and S. S. Heragu, “The facility layout problem," European Journal of Operational Research, vol. 29, no. 3, pp. 229-251, 1987.

[21] M. Djassemi, "Improving factory layout under a mixed floor and overhead material handling condition," Journal of Manufacturing Technology Management, vol. 18, no. 3, pp. 281-291, 2007.

[22] V. Deshpande, N. D. Patil, V. Baviskar, and J. Gandhi, "Plant layout optimization using CRAFT and ALDEP methodology," Productivity, vol. 57, article 32, no. 1, 2016. 


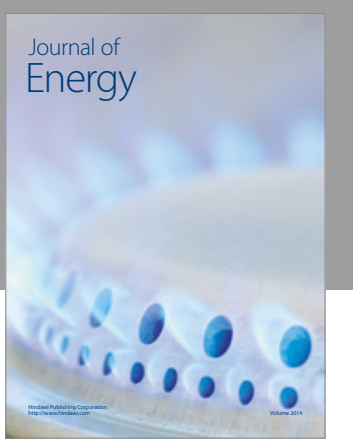

Journal of

Industrial Engineering
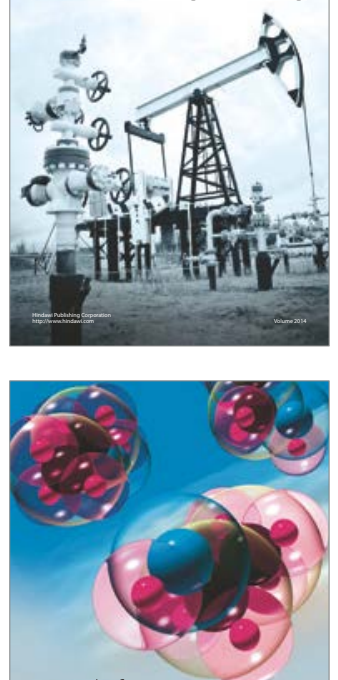

Fuels
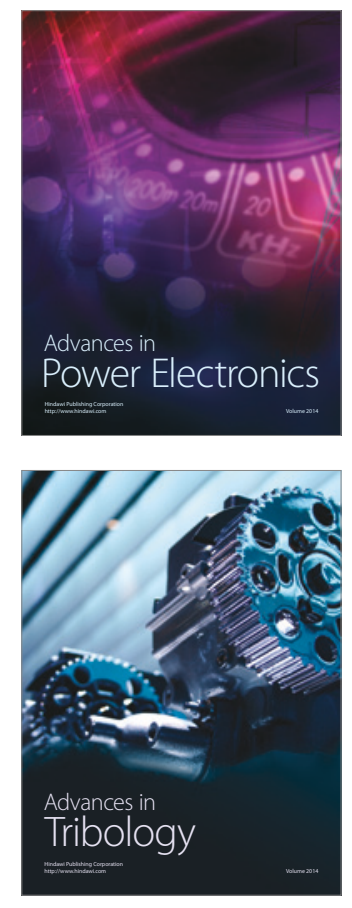
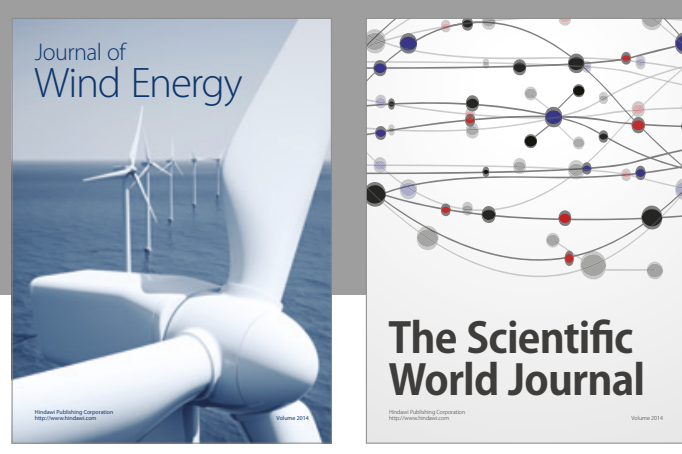

The Scientific World Journal
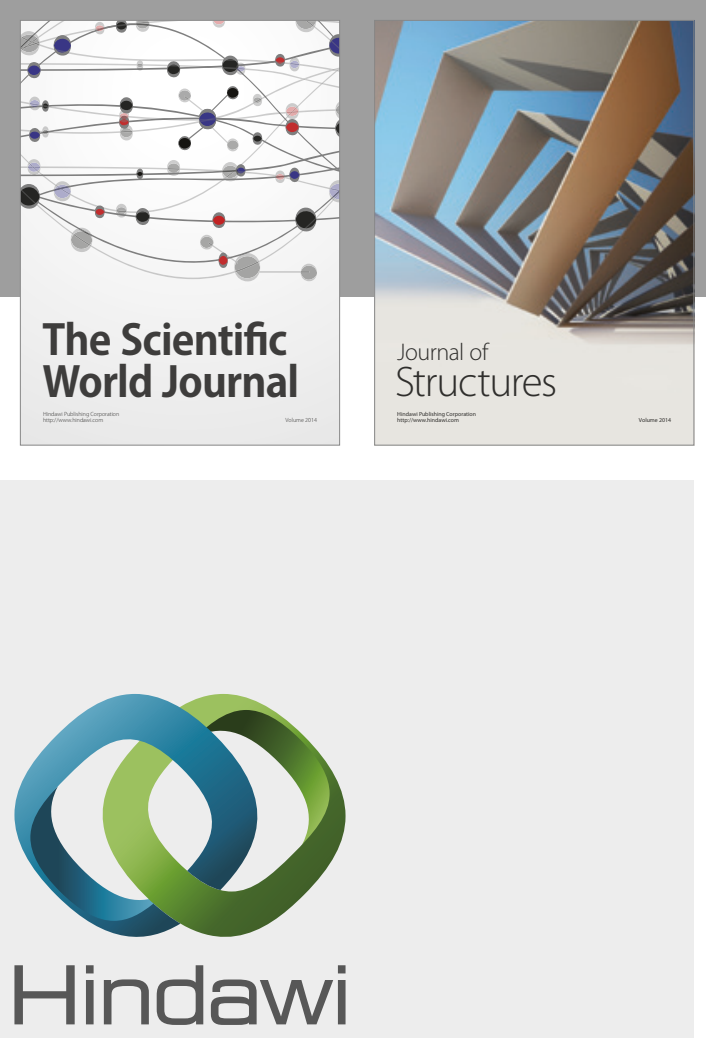

Submit your manuscripts at

https://www.hindawi.com
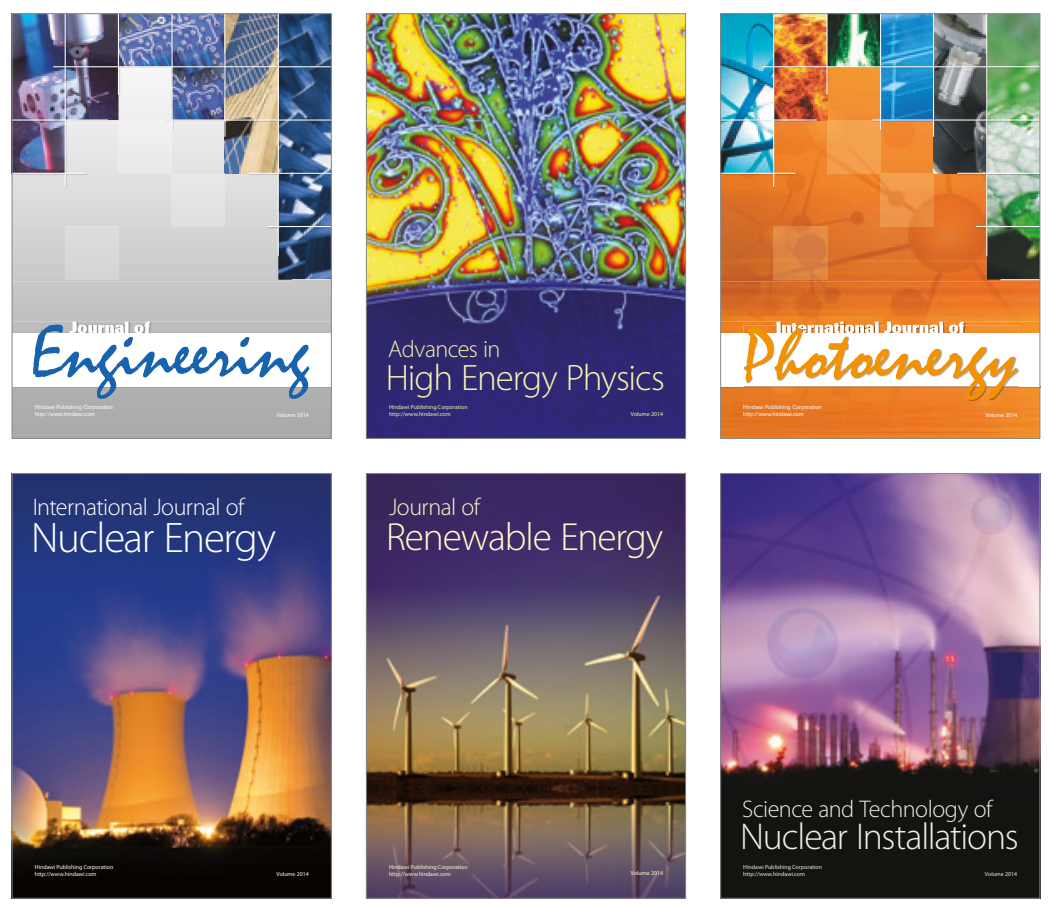

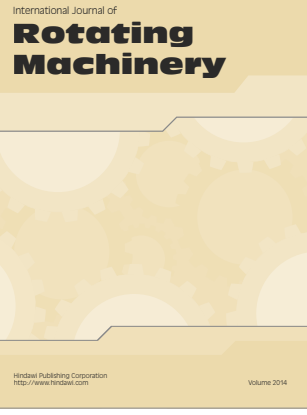

Journal of

Petroleum Engineering

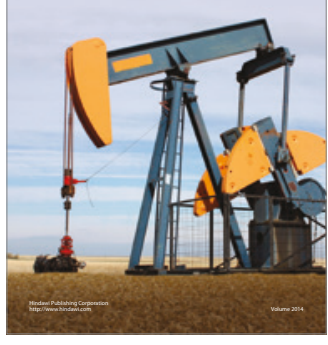

Journal of
Solar Energy
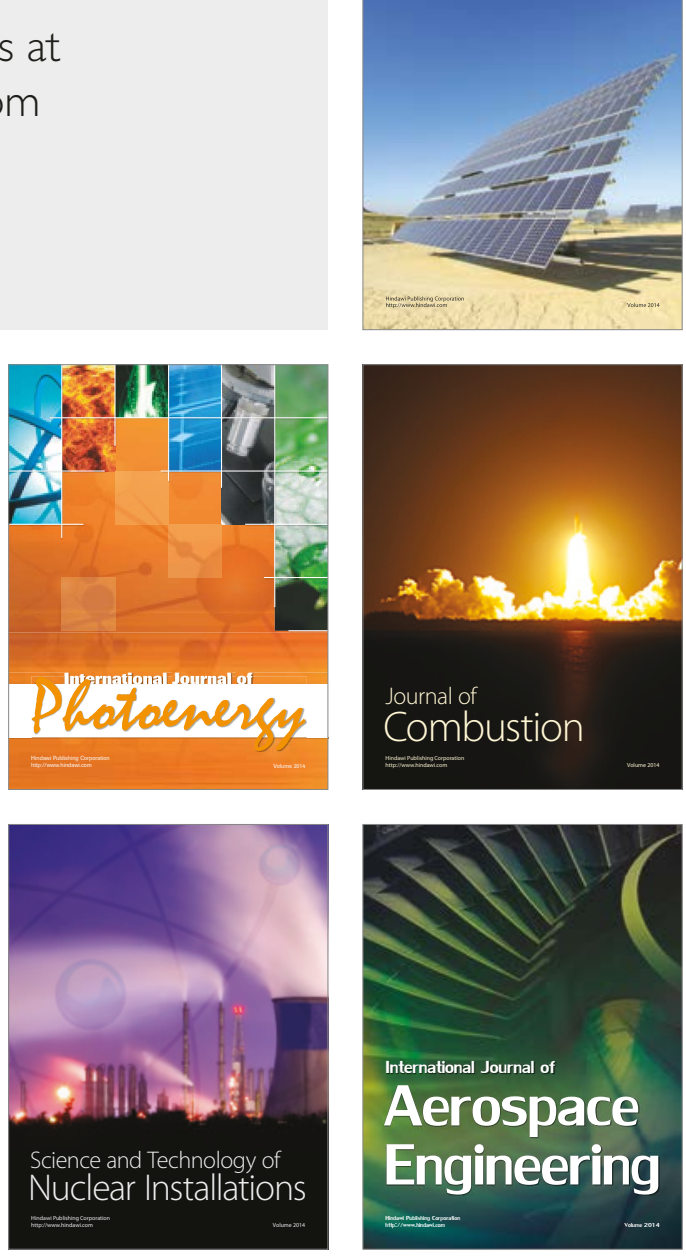